\title{
Estimating aquifer thickness using multiple pumping tests
}

Jean-Christophe Maréchal ${ }^{\mathrm{a}, \mathrm{b}, \mathrm{c}, \mathrm{d}^{*}}$, Jean-Michel Vouillamoz ${ }^{\mathrm{a}, \mathrm{e}}$, M.S. Mohan Kumar ${ }^{\mathrm{a}, \mathrm{f}}$, Benoit Dewandel $^{\mathrm{g}}$

${ }^{a}$ Indo-French Cell for Water Sciences, IISc-IRD Joint laboratory, Indian Institute of Science, 560012 Bangalore, India

${ }^{\mathrm{b}}$ Université de Toulouse ; UPS (OMP) ; LMTG; 14 Av Edouard Belin, F-31400 Toulouse, France

${ }^{\mathrm{c}}$ CNRS ; LMTG ; F-31400 Toulouse, France

${ }^{\mathrm{d}}$ IRD ; LMTG ; F-31400 Toulouse, France

${ }^{\mathrm{e}}$ LTHE, IRD, BP 53, 38041 Grenoble cedex 9, France

${ }^{\mathrm{f}}$ Department of Civil Engineering, Indian Institute of Science, 560012 Bangalore, India

${ }^{\mathrm{g}}$ brgm, 1039 rue de Pinville, 34000 Montpellier, France

\begin{abstract}
A method to estimate aquifer thickness and hydraulic conductivity has been developed, consisting of multiple pumping tests. The method requires short-duration pumping cycles on an unconfined aquifer with significant seasonal water-table fluctuations. The interpretation of several pumping tests at a site in India under various initial conditions provides information on the change in hydrodynamic parameters in relation to the initial water-table level. The transmissivity linearly decreases compared with the initial water level, suggesting a homogeneous distribution of hydraulic conductivity with depth. The hydraulic conductivity is estimated from the slope of this linear relationship. The extrapolation of the relationship between transmissivity and water level provides an estimate of the aquifer thickness that is in good agreement with geophysical investigations. The hydraulically active part of the aquifer is located in both the shallow weathered and the underlying densely fractured zones of the crystalline basement. However, no significant relationship is found between the aquifer storage coefficient and initial water level. This new method contributes to filling the methodological gap between single pumping tests and hydraulic tomography, in providing information on the variation of the global transmissivity according to depth. It can be applied to any unconfined aquifer experiencing large seasonal water-table fluctuations and short pumping cycles.
\end{abstract}

Keywords: groundwater hydraulics, India, crystalline rocks, fractured rocks, hydraulic testing

\section{Introduction}

Solving the inverse problem of common pumping test interpretation leads to the determination of the product of the hydraulic conductivity $K$ by the initial saturated thickness $b$ of the aquifer. This is the case in both confined (Theis 1935) or unconfined aquifer models (Neuman 1975). The solution of the problem is non unique and an infinite set of $K-b$ couples leads to the same transmissivity value $T=K b$. Therefore, additional information is required in order to solve the nonuniqueness of the solution.

In sedimentary rocks, the saturated thickness of the aquifer can be deduced from the geological log obtained during well drilling as hydrogeologic units can be defined from drilling cuttings or cores. In fractured crystalline rocks, the concept that groundwater flows mainly occur in a shallow higher-permeability zone ("active" zone) that overlies a deeper lower-permeability zone hosting little flow ("inactive" zone) is documented in mountainous regions (Mayo et al. 2003) and in flat bedrock areas (Davis and Turk 1964; Dewandel et al. 2006; Maréchal et al. 2004). The thickness of this more permeable layer is not well known as information from drilling does not always provide accurate indicators on the vertical 
extension of conductive fractures. Flowmeter measurements can provide information on the location of conductive fractures (Maréchal et al. 2004) but they can rarely be extended to a larger scale beyond the close vicinity of the well, except in cross-borehole flow logs (Paillet 1998). Comprehensive geophysical measurements, including appropriate borehole logging, are rarely carried out for small-scale groundwater development projects because such techniques are costly. However, the well-known and easy to implement rock electrical resistivity measurement (both logging in wells and measurements from the surface) can provide indirect information on the extension of the weathered/fissured and fractured zones (Chapellier 1987). Unfortunately, electrical resistivity measurements can hardly differentiate hydraulically active zones from clay-bearing ones.

Recently, the hydraulic tomography has been developed in order to improve the uniqueness of the inverse solution and reduce uncertainties in the identified hydraulic property field (Buttler et al. 1999; Gottlieb and Dietrich 1995). This method implies injection or pumping at various depths and various wells (i.e. sequential pumping tests) in order to provide additional information. If this new technique looks promising, it needs extensive field experiments and data processing for data inversion. The objective of the present paper is to explore the methodological gap between the common single pumping test modeled using classical Theis and Neuman models (whose results are strongly non-unique) and the hydraulic tomography method (whose application requires large investment).

Multiple pumping tests applied to the same unconfined aquifer using the same pumping and observation wells under various initial conditions are investigated. The complexity of periodic pumping with variable duration induces complicated signals which depend on the pumping history (Bangoy and Drogue 1994). Existing interpretation methods (i.e. Birsoy and Summers 1980) are valid for confined aquifers only. In this paper, one way of interpretation of such a data series is proposed for an unconfined aquifer. It is applied on a shallow fractured crystalline aquifer.

\section{Study area}

The numerous power cuts in rural India lead to the existence of daily pumping cycles in irrigation and village wells (Maréchal et al. 2006). The study site consists of two wells located in the Maddur watershed (south of Gundlupet), a rural area of south Karnataka, India (Figure 1). The geology belongs to the Precambrian Dharwar supergroup (Moyen et al. 2001) and consists of gneiss with amphibolites and quartz dykes. The pumping well (PW) provides domestic water to the village of Chenmallipur. Water is pumped every day using a submersible pump at the constant pumping rate, $Q=2.2 \pm 0.2 \mathrm{l} / \mathrm{s}$. Abandoned well CMP1 constitutes an observation well located 66 meters away from PW. These wells can be considered as fully penetrating, as their depths (> 50 and 72 meters, Table 1) are larger than the depth to the bottom of the fractured-weathered zone which is usually about $30-50$ meters in this geological context (Table 1).

The weathering profile of the gneissic hard-rock is constituted from the top to bottom by (Figure 2):

- A clayey-sandy saprolite, derived from prolonged in situ decomposition of bedrock, of 1- 2 meters thickness;

- A weathered and fractured layer which is generally characterized by a dense horizontal fissuring in the first few meters and a depth-decreasing density of fractures (Houston and Lewis 1988; Howard et al. 1992). Its thickness is unknown but it hardly ever exceeds tens of meters. 
- The fresh basement which is permeable only where tectonic fractures are present. At the catchment scale, this layer is generally considered as impermeable and of very low porosity (Maréchal et al. 2004).

The water table fluctuates between 3 and 25 meters depth, thus only within the fractured layer. It is therefore not restricted by any confining layer above it. The aquifer is a priori unconfined and bounded below by the fresh basement (aquiclude). The saturated thickness is not known.

Electrical resistivity tomography (ERT) has been carried out (location at Figure 1) to check the bottom of the weathered zone. A Wenner alpha array was implemented with 64 electrodes and an inter-electrode spacing of 4 meters in 2008. The inversion fits well with the calculated apparent resistivity data with a root mean square (RMS) of $2.2 \%$ (Figure 3 ).

The geological structure is homogeneous and relatively flat at the scale of the ERT, thus confirming that the use of a homogeneous analytical solution to interpret the pumping tests is appropriate. The depth to the bottom of the weathered rock is estimated with the $400-600$ $\Omega \mathrm{m}$ isocontour as calculated by Braun et al. (2009) and Descloitres et al. (2008) in a neighboring site. It ranges from 18 to 25 meters below ground surface. Resistivity values higher than 400 to $600 \Omega . \mathrm{m}$ are interpreted as fresh or fractured rock.

To assess if a fractured zone that can not be identified by the ERT is present below the isocontour of 400 - $600 \Omega . \mathrm{m}$, borehole electrical logging was carried out in CMP1 (Figure 4). The three normal probe (NL) measurements clearly reveal an interface at 19 meters below ground surface. Looking at the normal probe (NL) of $64 \mathrm{~cm}$ length that is less sensitive than the shorter probes to the groundwater resistivity, the values of apparent resistivity indicate weathered or fissured saturated rocks between the static water level (SWL) and 19 meters depth. This depth is in good agreement with that obtained from the ERT. Below 19 meters, the apparent resistivity ranges between 500 and $1000 \Omega$.m, thus indicating a fracture zone that extends down to 31 meters. At greater depths, apparent resistivity values over $1000 \Omega \mathrm{m}$ indicate not fractured basement rocks.

The duration of pumping cycles is determined by measuring the temperature of the outlet pipe of the pumping well (Massuel et al. 2009). The contrast between air and groundwater temperatures allows for identification of when the pumping starts and stops. A pumping phase is characterized by a steady temperature value close to groundwater temperature. A Thermochron iButton temperature logger with a time-step interval of 5 minutes was used at the pumping well. The discharge of the well was measured several times during the experiment in order to verify its constancy. The observation well was monitored using a water level data logger with a 10 minute time-step. Therefore, this set of wells constitutes a small autonomous experimental 'laboratory' for the analysis of multiple pumping tests. Pumping cycles analyzed in this study were selected at least 5 days after the last rainfall event in order to avoid any drainage effects.

\section{Method}

\subsection{Multiple pumping tests in unconfined aquifer}

When drawdown values in unconfined aquifers are plotted versus logarithm of time, they delineate an S-shape curve consisting of a steep segment at early times, a flat segment at intermediate times and a steeper segment at later times. This is caused by the delayed watertable response of the unconfined aquifer. Initially developed by Boulton [1970], the theory of "delayed yield from storage in unconfined aquifers" [Boulton and Pontin, 1971] was used by Neuman (1975) to develop an analytical solution adapted to anisotropic unconfined aquifers, where $K_{r}$ is the radial horizontal permeability and $K_{z}$ is the vertical permeability $\left(K_{r}=K_{z}\right.$ in the isotropic case). The Neuman model considers an infinite unconfined homogeneous aquifer 
with an initial saturated thickness $b$. When a complete well is pumped at a constant discharge rate $Q$, one part of the water comes from elastic storage in the aquifer and the other from gravitational drainage at the free surface (specific yield). The Neuman solution, plotted on type curves, provides reduced drawdowns $s_{D}$ in an observation well located at a radial distance $r$ from the pumping well, $s_{D}=4 \pi T s / Q$ as a function of (a) reduced time $t_{S}=T t / S r^{2}$ for a series of "type A" curves (Neuman 1975) at early times; and (b) reduced time $t_{y}=T t / S_{y} r^{2}$ for a series of "type B" curves at late times, where $T=K_{r} b \quad$ ( $T$ is the transmissivity of the aquifer), $S$ is the storage coefficient, $S_{y}$ is the specific yield, $t$ is the time since the start of pumping, and $s$ is the drawdown. Therefore, matching a type A curve on measured drawdown at early times leads to the estimate of $S$, while a type B curve at late times leads to $S_{Y}$.

The storage coefficient matched on the type A curve can be written as

$$
S=S_{S} b=\gamma(\alpha+\phi \beta) b
$$

where $\gamma=9.789 \times 10^{3} \mathrm{~N} / \mathrm{m}^{3}$ ( $\gamma$ is the specific weight of water at $20^{\circ} \mathrm{C}$ ), $\alpha$ is the compressibility of the rock, $\beta=4.4 \times 10^{-10} \mathrm{~m}^{2} / \mathrm{N}$ ( $\beta$ is the compressibility of water) and $\phi$ the porosity of the rock.

In an unconfined aquifer, the transmissivity varies with the saturated thickness of the aquifer $b$. Therefore, the interpretation of $n$ pumping tests conducted with various saturated aquifer thickness $b_{i}$ leads to $n$ values of the transmissivity $T_{i}=K_{r} b_{i}$, for $i=1,2, \ldots n$. The interpretation of multiple pumping tests precisely relies on the analysis of the relationship between $K_{r} b_{i}$ and $b_{i}$ (Figure 5).

Let us consider a homogeneous and isotropic unconfined aquifer with a maximum saturated thickness equal to $b_{\max }$ (corresponding to a minimum depth to water table $d_{\text {min }}$ ) measured after a long recharge period (Figure 5a); the transmissivity at that time is equal to $K_{r} b_{\max }$. During the dry season, the water table declines and the transmissivity decreases to $K_{r} b_{\min }$ along with the saturated thickness from $b_{\max }$ to $b_{\min }$. A series of pumping tests conducted at various dates during this period leads to a transmissivity ranging from $K_{r} d_{\max }$ to $K_{r} d_{\min }$. The $n$ plots of estimated transmissivity according to the initial water-table depth should align along a straight line with a slope inversely equal to the horizontal hydraulic conductivity $K_{r}$ of the aquifer (Figure $5 \mathrm{~b}$ ). The intercept of this straight line with the ordinates axis corresponds to the depth $d_{0}$ for which $K_{r} b=0$, corresponding to the bottom of the aquifer.

Multiple pumping tests carried out on the same borewell are rare, costly and difficult to implement. However pumping cycles induced by irrigation or drinking water supply wells can be easily monitored using automatic water level recorders installed in close observation wells. These intermittent pumping tests constitute an interesting and low-cost alternative technique to conducting multiple pumping tests. The multiple pumping tests method can then be applied in any region of the world with significant seasonal water table fluctuations (due to seasonal rainfall during monsoon for example) and relatively short water pumping cycles.

\subsection{Drawdown correction}

Under daily pumping cycles, the short duration of the recovery phase does not allow the system to recover to a static state before the next pumping phase. Therefore, the effect of previous pumping phases on the drawdown should be taken into account. Two methods have been tested for that purpose. The first method consists of interpreting several pumping and recovery phases using the superposition principle (Bangoy and Drogue 1994) in order to 
minimize the effect of non static initial conditions. However, increasing the duration of the interpretation window induces an increasing effect on the existing trends, i.e. depletion trend during dry season or increasing trend during monsoon. This leads to an overestimate of the transmissivity during the monsoon and to an underestimate during the dry season. Therefore, an alternative technique has been applied. For each pumping phase, the measured drawdown has been corrected from the previous recovery phase as illustrated in Figure 6 . The correction involves computing the drawdown with respect to the water level that would have been measured if the pumping had not have taken place (real drawdown), and not with respect to the initial water level (apparent drawdown). In order to reconstruct what would have been the water level, the previous recovery is extrapolated using an observed reference recovery (Figure 6). Then the real drawdown is computed, adding to the observed drawdown the remaining recovery $\Delta \mathrm{s}(\mathrm{t})$ which increases from 0 (at the beginning of the pumping phase, Figure 6) to $\Delta s_{\max }$ (at the end):

$$
s^{\prime}(t)=s(t)+\Delta s(t)
$$

where $s(t)$ is the observed apparent drawdown and $s^{\prime}(t)$ is the real drawdown corrected from the previous recovery phase. This technique is actually an application of the superposition principle valid for linear systems, which is not the case for an unconfined aquifer. Therefore the error introduced by this assumption on hydrodynamic parameters estimation should be computed. Practically, this error arises from the drawdown correction $\Delta s(\mathrm{t})\left(0<\Delta s(\mathrm{t})<\Delta s_{\max }\right)$ which contradicts the hypothesis of a constant aquifer thickness. Therefore the maximum uncertainty on estimated $\hat{K} b$ is

$$
\frac{\hat{K_{r} b}}{K_{r} b}=\frac{K_{r}\left(b+\Delta s_{\max }\right)}{K_{r} b}=1+\frac{\Delta s_{\max }}{b}
$$

where $\hat{K_{r} b}$ is the transmissivity estimated after drawdown correction and $K_{r} b$ the transmissivity that would have been obtained if no correction was necessary. The same uncertainty $\Delta s_{\max }$ has been applied to the initial water-table depth. However, pumping tests occurring after a recovery phase longer than 24 hours were not corrected as the water level reached its initial level: the uncertainty is nil for these cases. Uncertainties are represented by errors bars in Figures 10 and 11.

\section{Results}

The water-table fluctuations at well CMP1 during the monitoring period (January 2007 to August 2008) are presented Figure 7. The analysis of water-level signal leads to the identification of two components. The trends of high amplitude are linked to the sequence of dry and rainy seasons caused by the monsoon regime. Water-level fluctuations of lower amplitude (and higher frequency) are caused by short pumping cycles. The trend in watertable depth (between 2 and 25 meters below the surface) lends itself to being regarded as the initial water levels of short pumping cycles. This is precisely the needed condition for the application of the multiple pumping tests method described in this paper: existence of short duration pumping cycles on an aquifer with seasonal high amplitude water-table fluctuations. Consequently, each pumping cycle (identified by a serial number at Figure 7) can be interpreted as an individual short duration pumping test with varying initial conditions.

\subsection{Correction of the measured drawdown}

The reference recovery scenario used for correcting the recorded drawdown is the 19 hours-long recovery observed between 19th and 20th August 2008. This reference was chosen as it is the longest recovery recorded during the observation period and because it is located at 
an average water-table depth. The recovery correction was independently applied to each pumping test according to the duration of the previous pumping phase. Comparison between several pumping tests ( $a, b, c, d$ and e, see Figure 8 for the dates) with close initial water levels and different previous recovery phases shows that the corrected drawdowns are very similar (Figure 8). The difference compared with uncorrected apparent drawdown is about 22 $\%$. The coefficient of variation $C V$ of the corrected drawdown has been computed at every time step $t$ as the ratio:

$$
C V(t)=\frac{\sigma\left(s_{a}^{\prime}(t), s_{b}^{\prime}(t), s_{c}^{\prime}(t), s_{d}^{\prime}(t), s_{e}^{\prime}(t)\right)}{\mu\left(s_{a}^{\prime}(t), s_{b}^{\prime}(t), s_{c}^{\prime}(t), s_{d}^{\prime}(t), s_{e}^{\prime}(t)\right)}
$$

with $\sigma$ the standard deviation and $\mu$ the average of corrected drawdown $s^{\prime}$ during pumping tests a, b, c, d and e at time $t . C V$ tends to quickly decrease and becomes inferior to $10 \%$ at early times (>2500 s, Figure 8). This shows that the effects of previous recovery phases have been successfully corrected. It also suggests a very good repeatability of pumping cycle results.

\subsection{Interpretation of the corrected drawdown}

The drawdown derivatives (diagnostic plot) of four pumping cycles and one recovery with variable initial conditions are compared in Figure 9.

The equation used to calculate the drawdown derivative at the point of interest, $i$, is (Bourdet et al. 1989):

$$
\left(\frac{d s^{\prime}}{d X}\right)_{i}=\frac{\left(\frac{\Delta s_{1}^{\prime}}{\Delta X_{1}} \Delta X_{2}+\frac{\Delta s_{2}^{\prime}}{\Delta X_{2}} \Delta X_{1}\right)}{\Delta X_{1}+\Delta X_{2}}
$$

where $1=$ point before $i, 2=$ point after, $X$ is time function $(\ln \Delta t)$, and $s^{\prime}$ is the corrected drawdown. Noise effects are reduced by choosing the points 1 and 2 where the derivative is calculated sufficiently distant from point $i$.

Figure 9 does not show the U-shape curve typical of delayed yield response of the unconfined aquifer. This is due to the relative short duration of the pumping cycles and the quite long distance between observation and pumping wells. In Fig 9 the general trend is a stabilization of the derivative, corresponding to the early-times type A curve of the Neuman model.

One can also observe that the deeper the initial water level, the higher the derivative plateau (Figure 9). This shows a decrease of the transmissivity with the water-table decline since $K_{r} b$ can directly be estimated from the derivative plateau (Chow 1952):

$$
\frac{\partial s^{\prime}}{\partial \ln (t)}=\frac{Q}{4 \pi K_{r} b}
$$

Drawdown matches successfully the type A curves of the Neuman model for early times as suggested by the diagnostic plot. The results of the interpretation of $n=24$ pumping phases between January 2007 and August 2008 for CMP1 are given at Erreur ! Source du renvoi introuvable. 


\section{Discussion}

\subsection{Hydraulic conductivity and aquifer thickness}

Within the investigated range of water-level depths $\left(3.45<d_{i}<20.63 \mathrm{~m}\right)$, the calculated transmissivity $T_{i}=K_{r} b_{i}$ (for $i=1$ to 24 ) reasonably matches a linear relationship with the initial depth to water level $d_{i}$ (Figure 10). The deeper initial water level gives the lower value of transmissivity. The observed linear relationship suggests that the horizontal hydraulic conductivity $K_{r}$ is constant with depth. Hydraulic conductivity $K_{r}$ can be calculated as the inverse slope of the fitted line as suggested earlier in Figure 5b. One linear regression is calculated (Figure 10): the inverse slope of the linear regression is $K_{r}=3.1_{-0.7}^{+1.4} \times 10^{-6} \mathrm{~m} / \mathrm{s}$ (correlation coefficient $R=0.83$ ). This value is similar to other results obtained for the Indian Shield from slug tests $\left(\mathrm{K}=4.4 \times 10^{-6} \mathrm{~m} / \mathrm{s}\right.$, Maréchal et al. 2004) and pumping tests $(\mathrm{K}=1 \mathrm{x}$ $10^{-5} \mathrm{~m} / \mathrm{s}$, Maréchal et al. 2004). The extrapolation of this linear relationship for $K_{r} b=0$ provides the depth at which $b=0$, that is the depth to the bottom of the aquifer $d_{0}=26.9 \pm 4.5$ m (Figure 10).

\subsection{Specific storage}

No clear relationship appears between calculated storage $S_{s} b_{i}$ and the water-table depth (Figure 11). However, the obtained values range from $1.4 \times 10^{-4}$ to $3.6 \times 10^{-4}$ and are close to the mean storage value obtained for the Indian Shield for granite $\left(4.8 \times 10^{-4}\right.$, Maréchal et al. 2004). Assuming $\phi \approx 0.02$ (Maréchal et al. 2006) in Eq. (1), $\alpha=10^{-9} \mathrm{~m}^{2} / \mathrm{N}$ (ranging from $10^{-8}$ to $10^{-10}$ for fractured rock according to Kruseman and Ridder (1990)) and $b=20 \mathrm{~m}$, one obtains $S=2 \times 10^{-4}$ which is very close to the values obtained using the Neuman model on drawdown curves of short duration pumping tests. It is clear that the short duration pumping tests do not lead to the estimate of specific yield but rather to the estimate of elastic storage. Longer duration pumping tests are needed to determine the specific yield $S_{y}$ of the aquifer using the delayed yield approach (Neuman 1975).

The lack of linear relationship between storage and water-table depth suggests that the specific storage is not homogeneous in this aquifer. As a consequence, the hydraulic diffusivity $(T / S)$ is not constant as well.

\subsection{Comparison with geophysical data}

Geophysical measurements suggest that the rock is weathered and highly fractured down to 19 meters below ground surface, and then the rock is moderately fractured down to 31 meters deep. This result is in good agreement with the depth to the bottom of the aquifer obtained from the pumping test analysis $\left(d_{0}=26.9 \pm 4.5 \mathrm{~m}\right)$. It suggests that the hydraulically active part of the aquifer is only located in the shallow weathered and densely fractured zones of the crystalline basement (Maréchal 2009). This result also confirms other findings obtained in crystalline aquifers from Africa (Chilton and Foster 1995; Houston and Lewis 1988; Taylor and Howard 2000), the United States (Davis and Turk 1964) and India (Dewandel et al. 2006; Maréchal et al. 2004).

\section{Conclusion}

Multiple pumping tests carried out on the same unconfined aquifer under various initial conditions (initial water level) allow characterization of various responses of the system. Interpretation of short-duration pumping phases shows that the transmissivity decreases linearly with the increase of water-table depth. The extrapolation of this linear relation allows for estimation of the aquifer thickness. The main advantage of this method is that it provides 
the thickness of the really hydraulically active part of the aquifer. For the analyzed data set, the obtained thickness is consistent with the local thickness of weathered fractured rocks estimated using geophysical methods.

The main limitation of this method is that it requires high amplitude seasonal water-level fluctuations. This method can be applied to other types of unconfined aquifer, for example, aquifers present in sedimentary rocks. The use of longer pumping cycles would allow for estimation of the total set of hydrodynamic parameters, including specific yield and the permeability anisotropy ratio of the unconfined aquifer.

\section{Acknowledgments}

The Maddur Basin study is part of the ORE-BVET project (Observatoire de Recherche en Environnement - Bassin Versant Expérimentaux Tropicaux). Apart from specific support from the French Institute of Research for Development (IRD), the Embassy of France in India and the Indian Institute of Science, our project benefited from funding from IRD and INSU/CNRS (Institut National des Sciences de l'Univers / Centre National de la Recherche Scientifique) through the French programmes ECCO-PNRH (Ecosphère Continentale: Processus et Modélisation - Programme National Recherche Hydrologique) and EC2CO (Ecosphère Continentale et Côtière). It is been funded by IFCPAR (Indo-French Center for the Promotion of Advanced Research W-3000) and supported by ANR (National Research Agency, France) under VMCS Programme No ANR-08-VULN-010-03/SHIVA. The multidisciplinary research carried out on the Maddur watershed began in 2005 under the control of the IISc/IRD laboratory IFCWS (Indo-French Cell for Water Sciences). The authors warmly thank M. Sekhar, S. Subramanian and J.J. Braun for their support. The contribution of Associate Editor Nadim Copty and Thomas Graf was highly appreciated.

\section{References}

Bangoy, L.M. and Drogue, C., 1994. Analysis of intermittent pumping tests in fissured fractal aquifers: theory and applications. Journal of Hydrology, 158(1-2): 47-59.

Birsoy, Y.K. and Summers, W.K., 1980. Determination of Aquifer Parameters from Step Tests and Intermittent Pumping Data. Ground Water, 18(2): 137-146.

Boulton, N. S. (1970), Analysis of data from pumping tests in unconfined anisotropic aquifers, Journal of Hydrology, 10, 369-378.

Boulton, N. S., and J. M. A. Pontin (1971), An extended theory of delayed yield from storage applied to pumping tests in unconfined anisotropic aquifers, Journal of Hydrology, 14, 53-65.

Bourdet, D., Ayoub, J.A. and Pirard, Y.M., 1989. Use of pressure derivative in well-test interpretation. SPE Formation Evaluation, 4(2): 293-302.

Braun, J.J., Descloitres, M., Riotte, J., Fleury, S., Barbiero, L., Boeglin, J.L., Violette, A., Lacarce, E., Ruiz, L., Sekhar, M., Kumar, M.S.M., Subramanian, S. and Dupree, B., 2009. Regolith mass balance inferred from combined mineralogical, geochemical and geophysical studies: Mule Hole gneissic watershed, South India. Geochimica Et Cosmochimica Acta, 73(4): 935-961.

Butler, J.J., Jr., McElwee, C.D. and Bohling, G.C., 1999. Pumping tests in networks of multilevel sampling wells: Motivation and Method. Water Resources Research, 35(11): 3553-3560.

Chapellier, D., 1987. Diagraphies appliquées à l'hydrologie [Wells logging applied to hydrology]. Lavoisier, Paris.

Chilton, P.J. and Foster, S.S.D., 1995. Hydrogeological characteristics and water-supply potential of basement aquifers in Tropical Africa. Hydrogeology Journal, 3(1): 3-49. 
Chow, V.T., 1952. On the determination of transmissibility and storage coefficients from pumping test data. Trans Am Geophys Union, 33: 397-404.

Davis, S.N. and Turk, L.J., 1964. Optimum depth of wells in crystalline rocks. Groundwater, 2(2): 6-11.

Descloitres, M., Ruiz, L., Sekhar, M., Legchenko, A., Braun, J.J., Mohan Kumar, M.S. and Subramanian, S., 2008. Characterization of seasonal local recharge using electrical resistivity tomography and magnetic resonance sounding. Hydrological Processes, 22(3): 384-394.

Dewandel, B., Lachassagne, P., Wyns, R., Marechal, J.C. and Krishnamurthy, N.S., 2006. A generalized 3-D geological and hydrogeological conceptual model of granite aquifers controlled by single or multiphase weathering. Journal of Hydrology, 330(1-2): 260284.

Gottlieb, J. and Dietrich, P., 1995. Identification of the permeability distribution in soil by hydraulic tomography. Inverse Problem, 11: 353-360.

Houston, J.F.T. and Lewis, R.T., 1988. The Victoria Province Drought Relief Project, II. Borehole Yield Relationships. Ground Water, 26(4): 418-426.

Howard, K.W.F., Hughes, M., Charlesworth, D.L. and Ngobi, G., 1992. Hydrogeologic Evaluation Of Fracture Permeability In Crystalline Basement Aquifers Of Uganda. Hydrogeology Journal, 1(1): 55-65.

Kruseman, G.P. and Ridder, N.A., 1990. Analysis and evaluation of pumping test data. ILRI Publication., 377 pp.

Maréchal, J.C., 2009. Editor's message: the sunk cost fallacy of deep drilling. Hydrogeology Journal, 18: 287-289, doi: 10.1007/s10040-009-0515-2.

Maréchal, J.C., Dewandel, B., Galeazzi, L., Bournet, G. and Ahmed, S., 2006. Combined estimation of specific yield and natural recharge in a semi-arid groundwater basin with irrigated agriculture. Journal of Hydrology, 329(1-2): 281-293.

Maréchal, J.C., Dewandel, B. and Subrahmanyam, K., 2004. Use of hydraulic tests at different scales to characterize fracture network properties in the weathered-fractured layer of a hard rock aquifer. Water Resources Research, 40(11).

Massuel, S., Perrin, J., Wajid, M., Mascre, C. and Dewandel, B., 2009. A Simple, Low-Cost Method to Monitor Duration of Ground Water Pumping. Ground Water, 47(1): 141145.

Mayo, A.L., Morris, T.H., Peltier, S., Petersen, E.C., Payne, K., Holman, L.S., Tingey, D., Fogel, T., Black, B.J., Gibbs, T.D. (2003) Active and inactive groundwater flow systems: evidence from a stratified, mountainous terrain. GSA Bull 115(12):14561472

Moyen, J.F., Martin, H. and Jayananda, M., 2001. Multi- element geochemical modeling of crust-mantle interactions during late-Archean crustal growth: the Closepet Granite (South India). Precambrian Research, 112: 87-105.

Neuman, S.P., 1975. Analysis of Pumping Test Data From Anisotropic Unconfined Aquifers Considering Delayed Gravity Response. Water Resources Research, 11(2): 329-342.

Paillet, F.L., 1998. Flow modeling and permeability estimation using borehole flow logs in heterogeneous fractured formations. Water Resources Research, 34(5): 997-1010.

Taylor, R. and Howard, K., 2000. A tectono-geomorphic model of the hydrogeology of deeply weathered crystalline rock: Evidence from Uganda. Hydrogeology Journal, 8(3): 279-294.

Theis, C.V. 1935. The relationship between the lowering of the piezometric surface and the rate and duration of discharge of a well using groundwater storage. Eos Trans. AGU, $16,519$. 


\section{Figures}

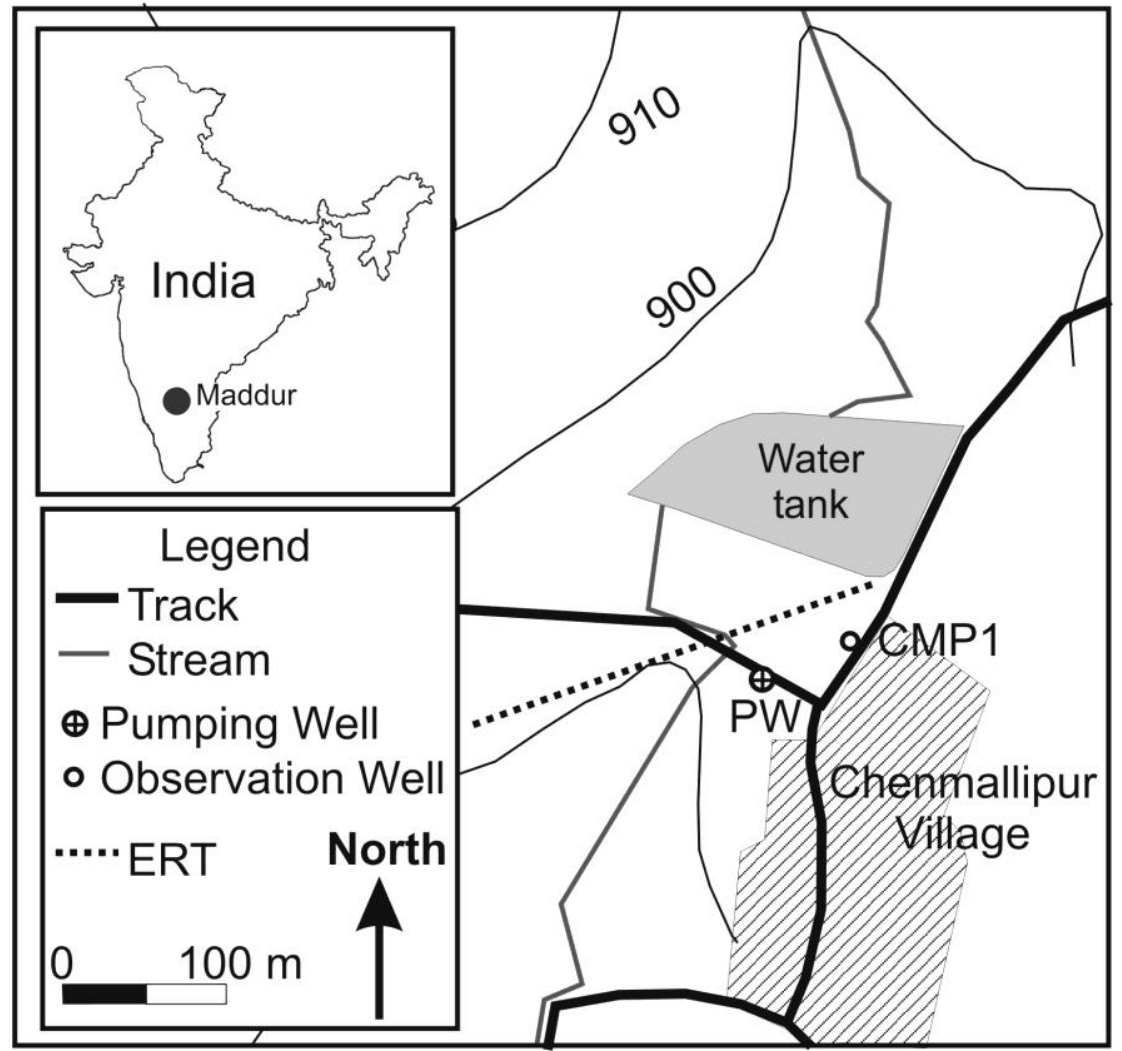

Figure 1: Location of the multiple pumping tests experimental site and the electrical resistivity tomography (ERT) profile in Maddur watershed SW

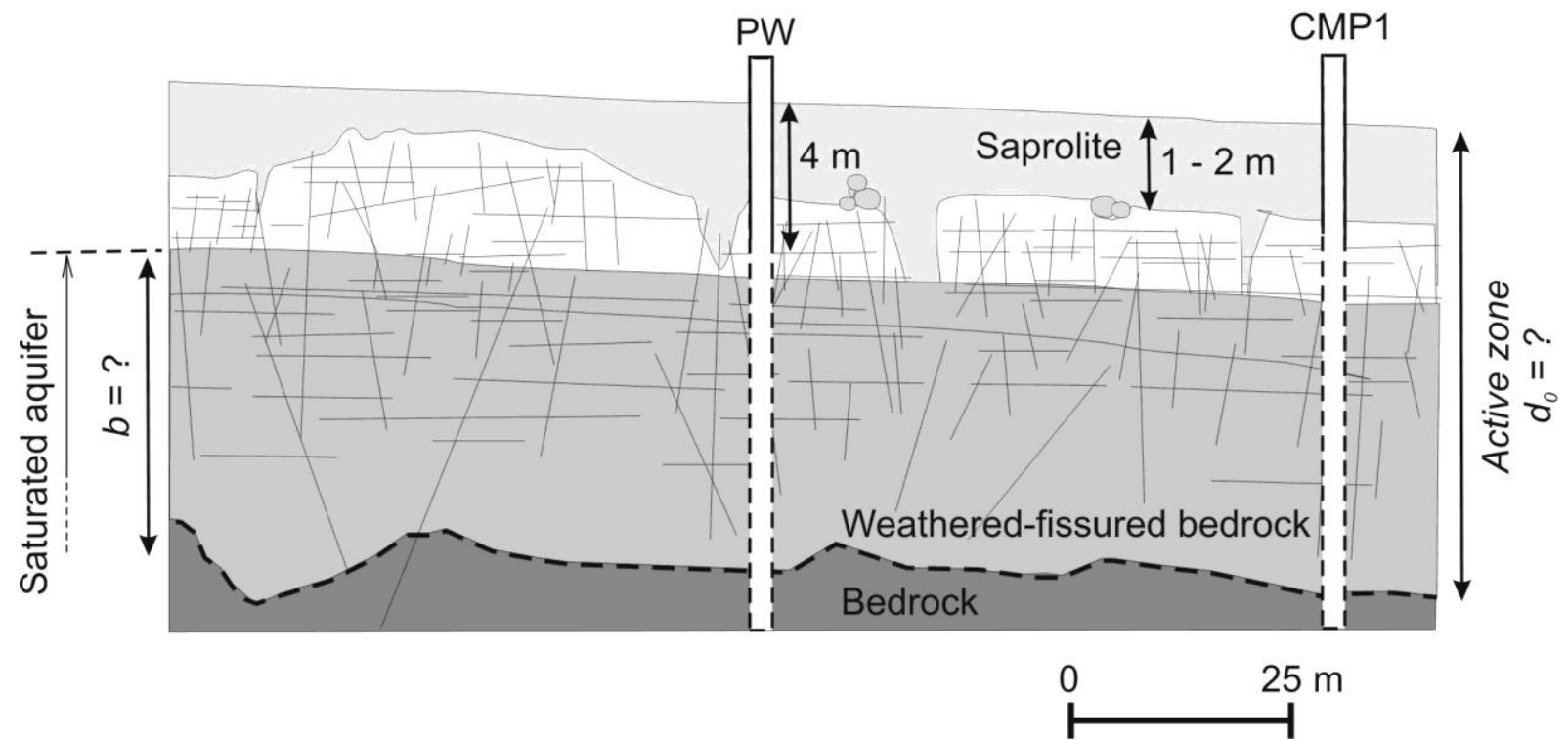

Figure 2: Hydrogeological section of the pumping site ( $d_{0}$ : depth to the bottom of the aquifer) 


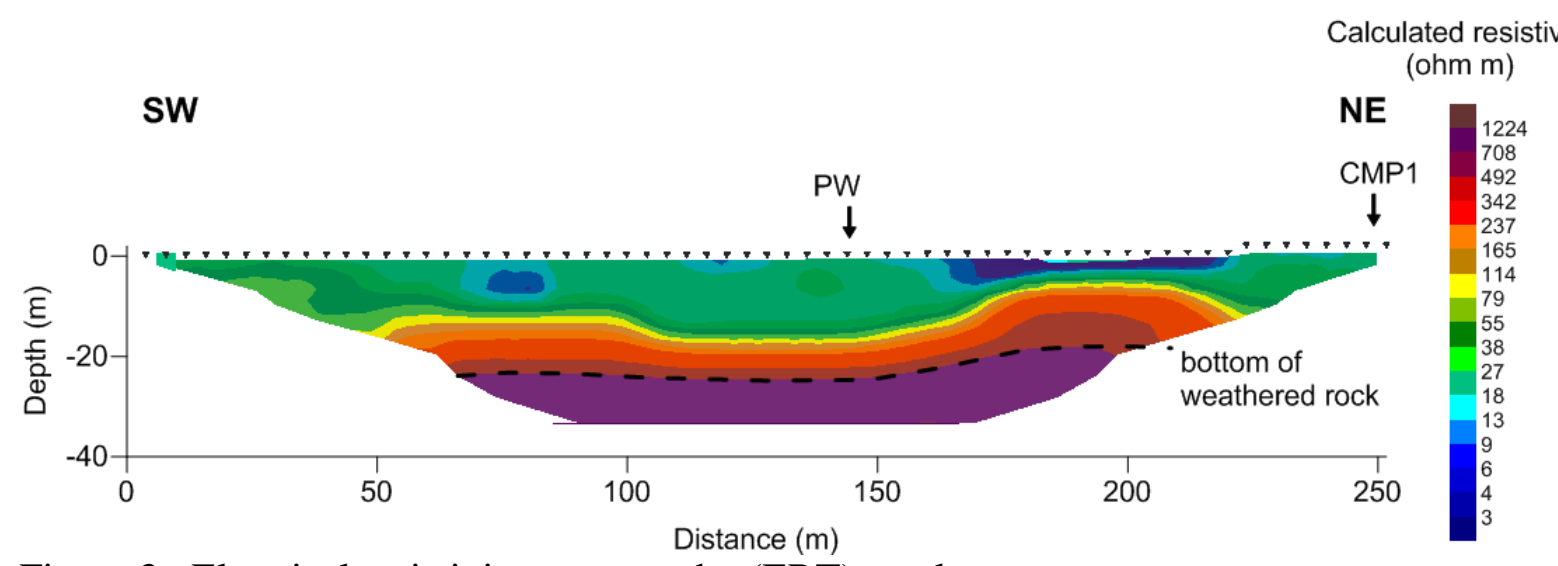

Figure 3: Electrical resistivity tomography (ERT) results

Apparent resistivity

$(\Omega \mathrm{m})$

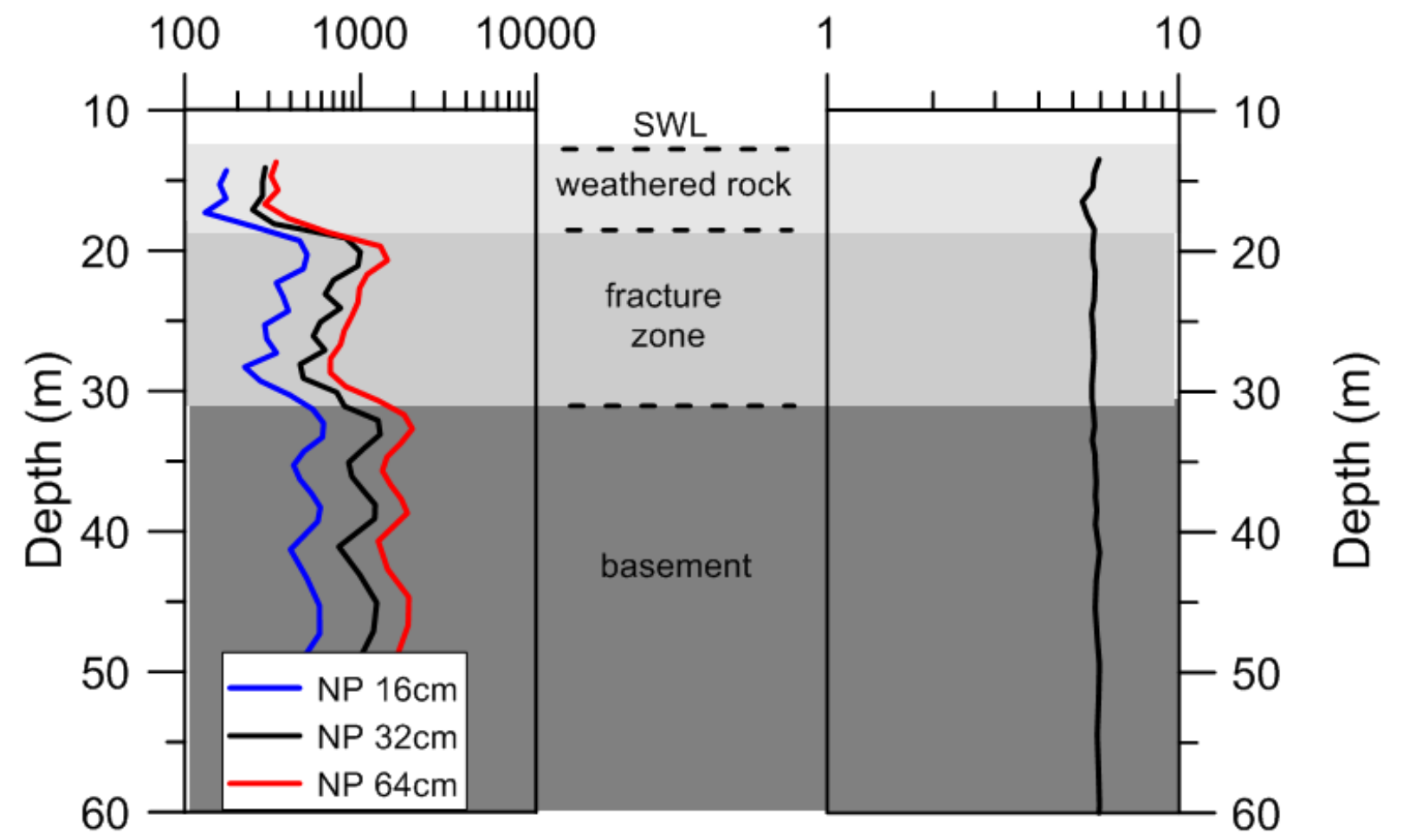

Water resistivity

$(\Omega \mathrm{m})$

Figure 4: Electrical logging (CMP1, NP16, NP32 and NP64 are the lengths in $\mathrm{cm}$ of the used probe) 


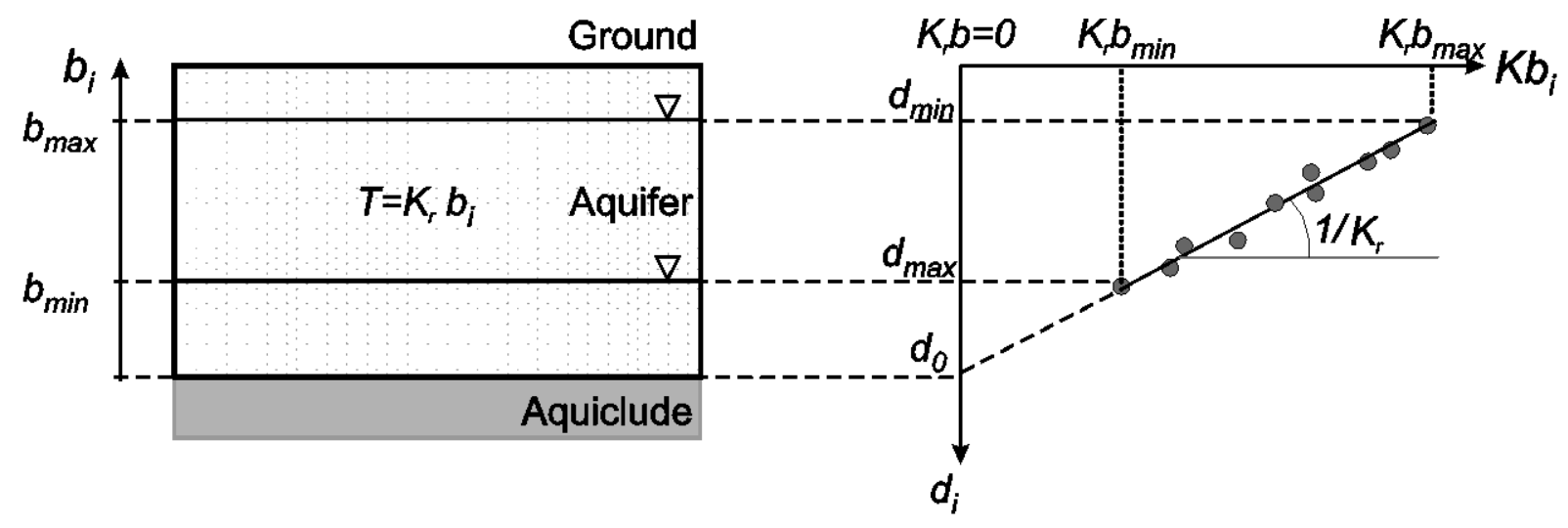

(a)

(b)

Figure 5: (a) Unconfined aquifer with variable initial conditions of saturated thickness $b_{i}$ (b) linear decrease of transmissivity with depth to water table; $d_{i}$ is the depth to water table

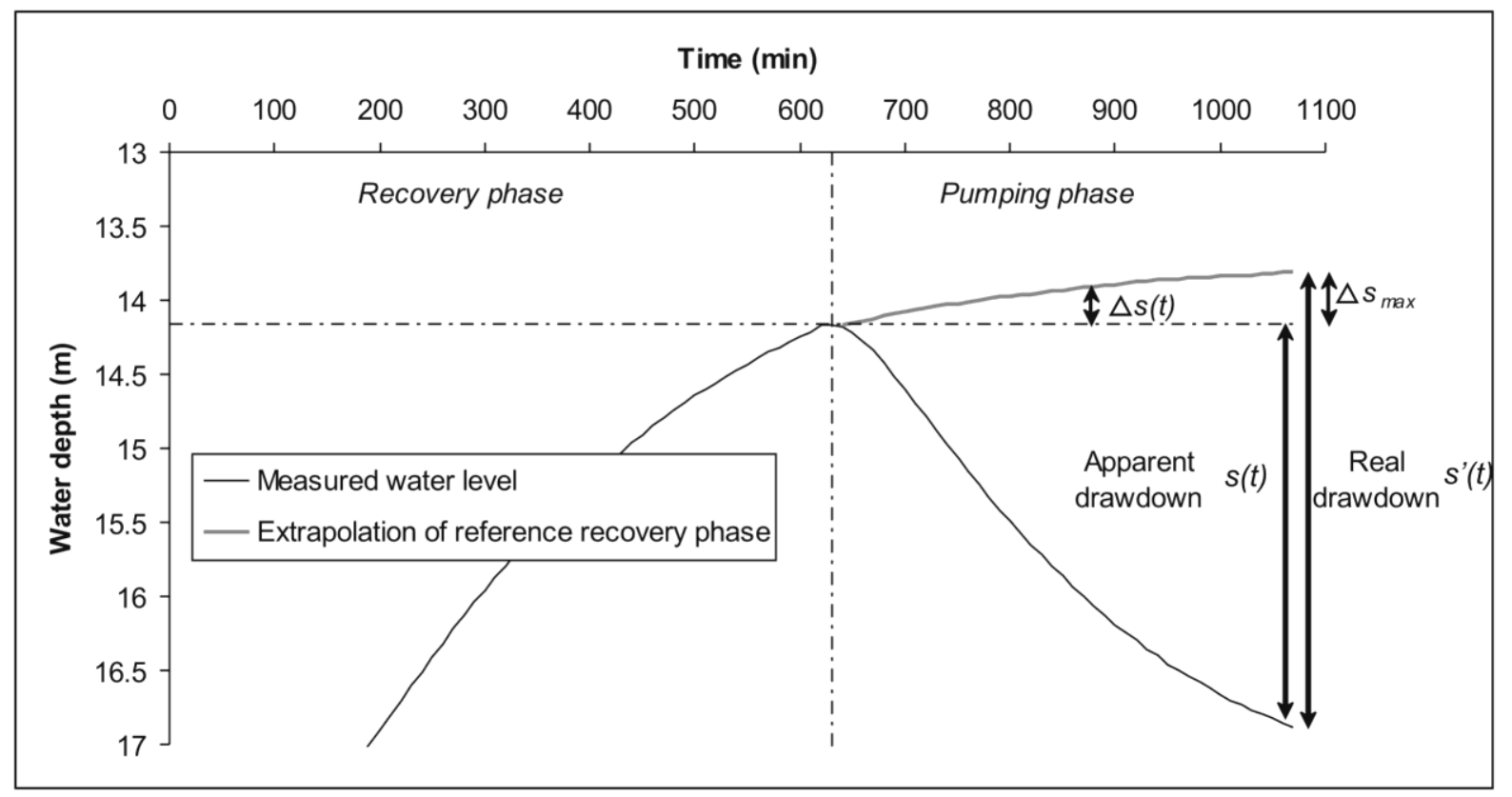

Figure 6: Example of a drawdown corrected with respect to the recovery effect 


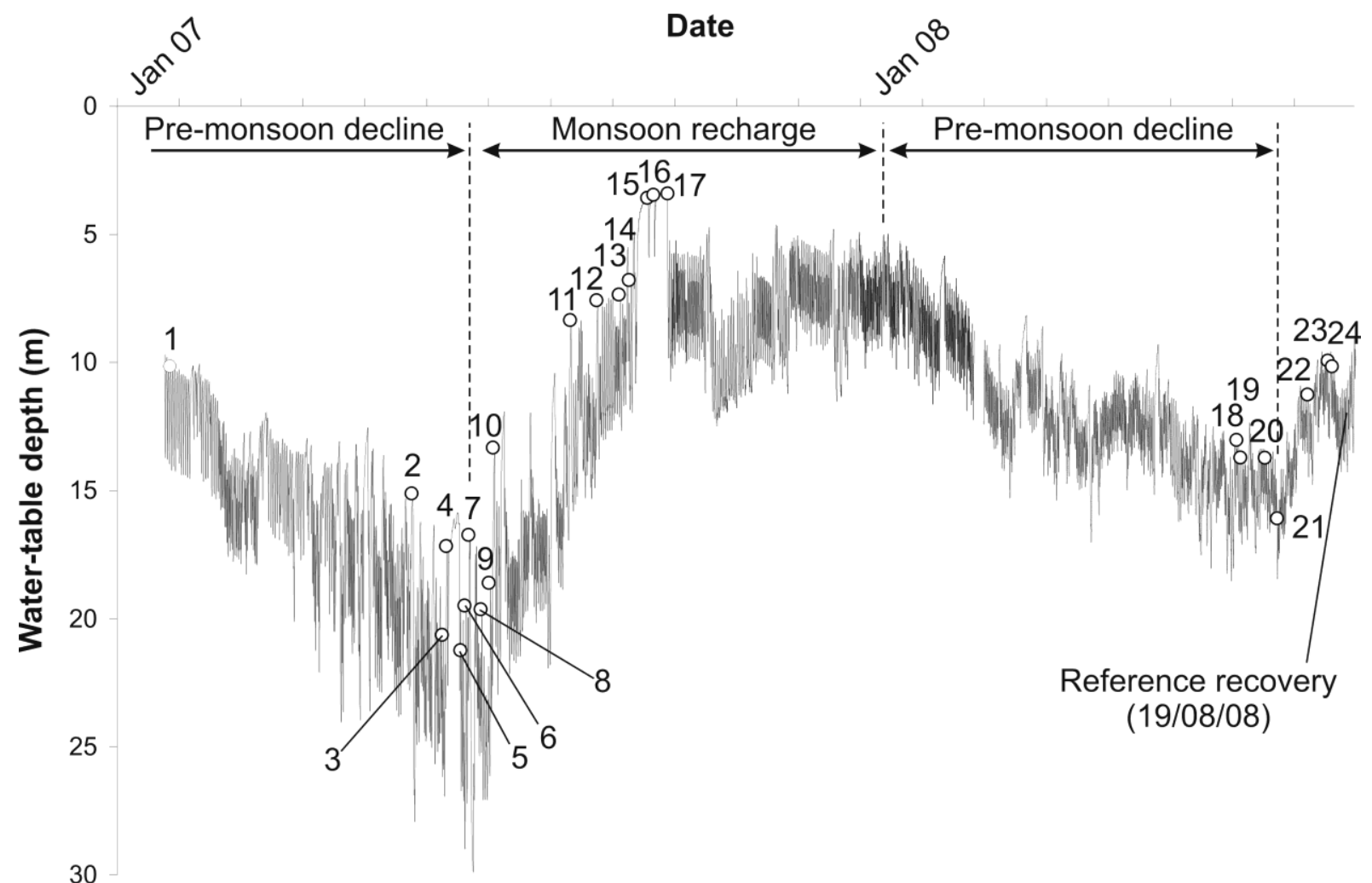

Figure 7: Water-table depth fluctuations at CMP1 during the monitoring period (analyzed pumping cycles are numbered according to Table 2).

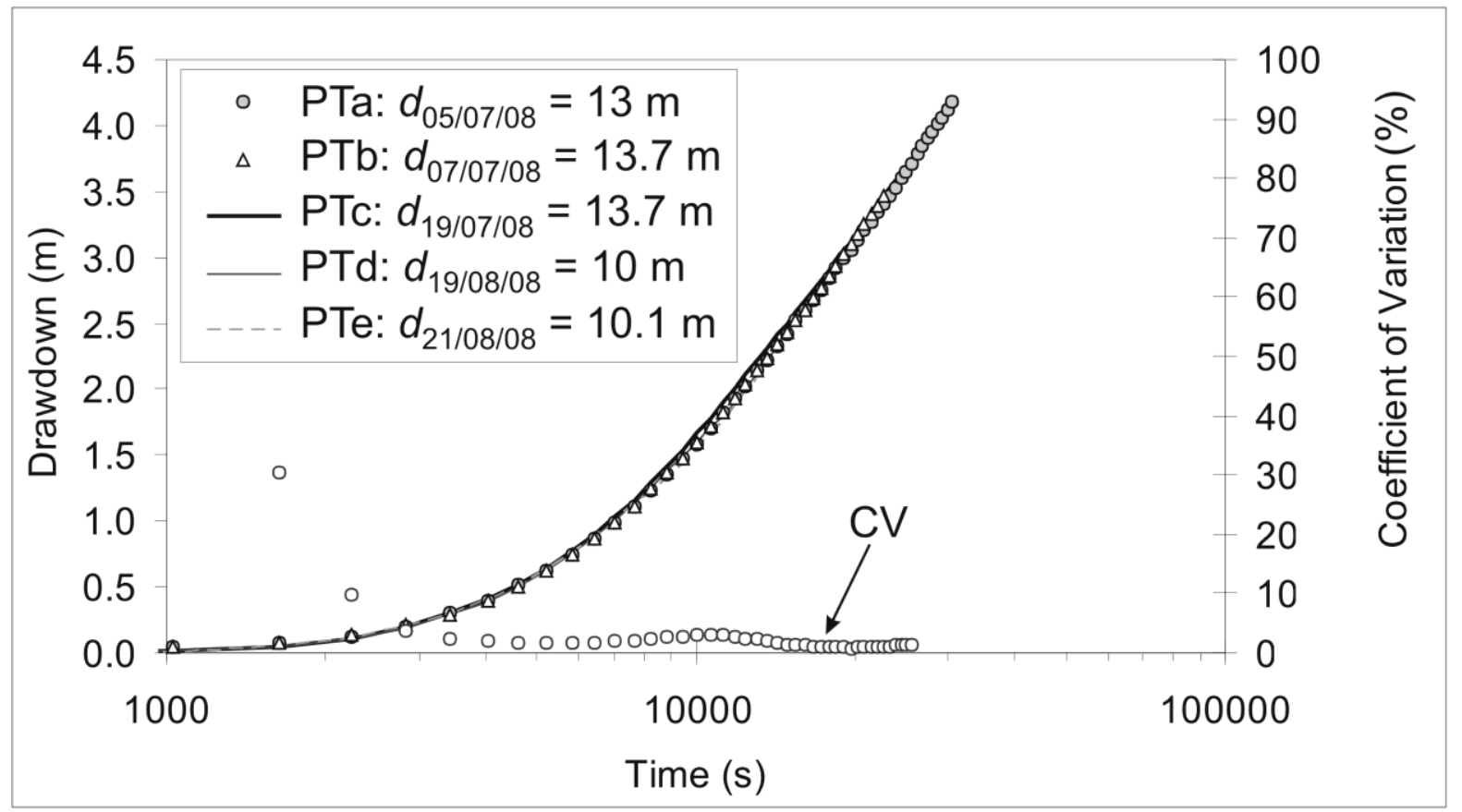

Figure 8: Corrected drawdown at CMP1 well during five pumping tests (PT) between 5th July and 21st August 2008, with similar initial conditions (initial water-level depth $d$ ranging from 10 to $14 \mathrm{~m}$ ) 


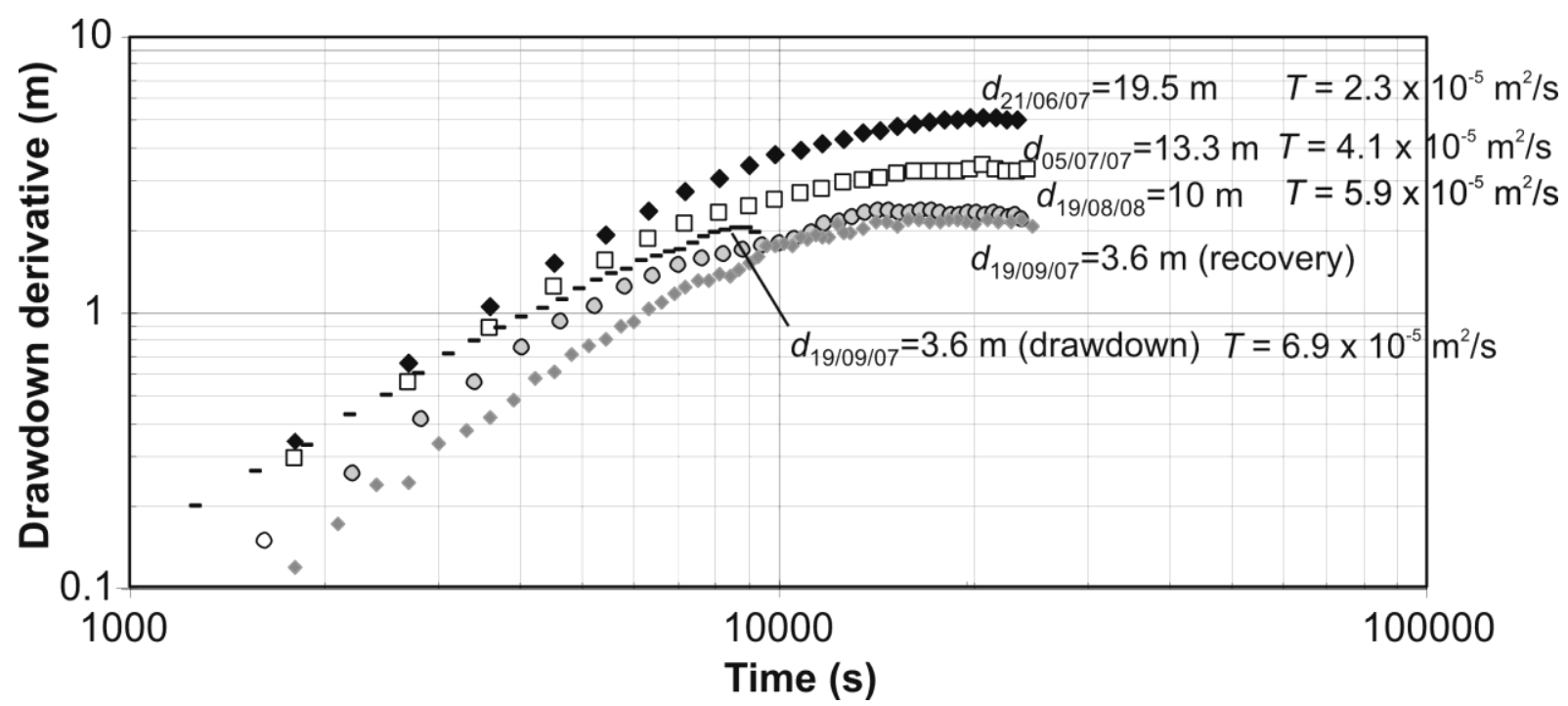

Figure 9: Drawdown derivative of several pumping cycles starting with variable initial watertable depths

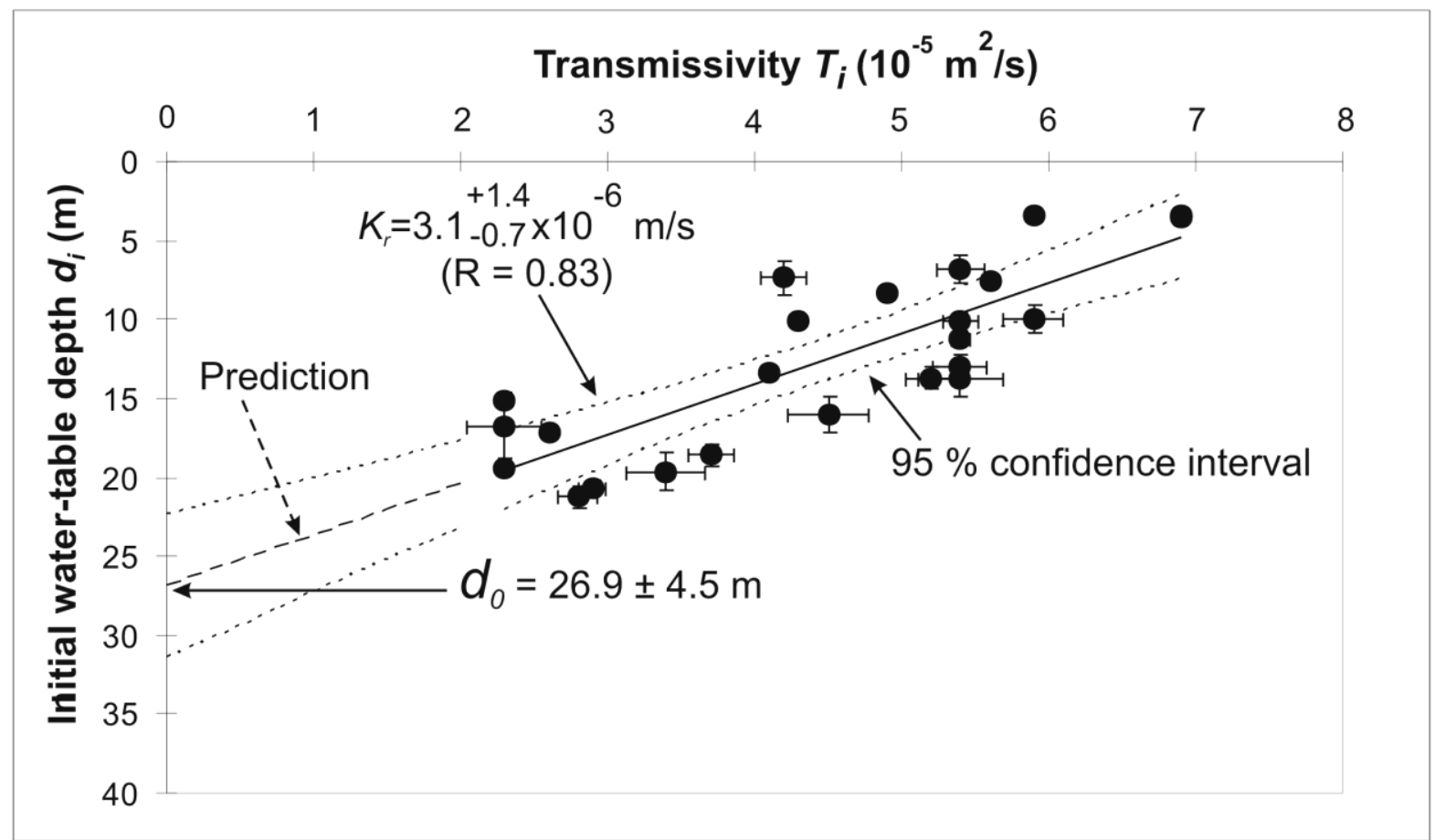

Figure 10: Transmissivity obtained from multiple pumping tests at CMP1 as a function of initial water-table depth 


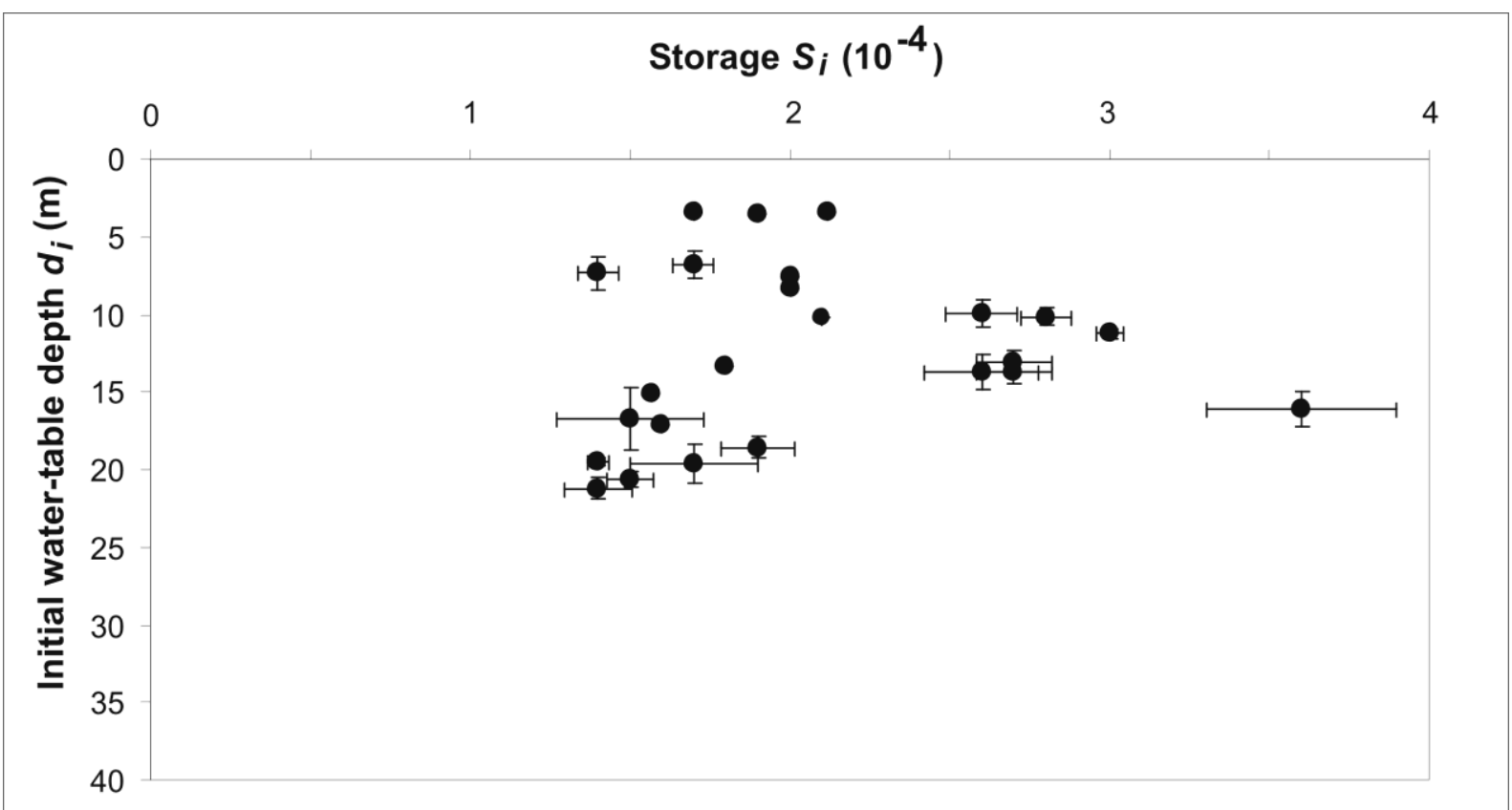

Figure 11: Storage coefficient obtained from multiple pumping tests at CMP1 as a function of initial water-table depth 


\section{Tables}

Table 1: Characteristics of monitored wells

\begin{tabular}{|c|c|c|c|c|c|}
\hline Well & Type & $\begin{array}{c}\text { Diameter } \\
(\mathrm{m})\end{array}$ & $\begin{array}{c}\text { Depth } \\
(\mathrm{m})\end{array}$ & $\begin{array}{c}\text { Distance to } \\
\text { PW }(\mathrm{m})\end{array}$ & $\begin{array}{c}\text { Monitoring } \\
\text { device }\end{array}$ \\
\hline PW & $\begin{array}{c}\text { Pumping } \\
\text { well }\end{array}$ & 0.165 & $>50$ & - & Thermochron iButton \\
\hline CMP1 & $\begin{array}{c}\text { Observation } \\
\text { well }\end{array}$ & 0.165 & 72 & 66 & Water level data logger \\
\hline
\end{tabular}

Table 2: Results of the interpretation of $n=24$ pumping cycles at CMP1 using the Neuman model. $i$ is the pumping cycle number (see Figure 7). $T_{i}$ and $S_{i}$ respectively transmissivity and storage coefficient calculated from $\mathrm{i}^{\text {th }}$ pumping cycle.

\begin{tabular}{|c|cc|cc|}
\hline$i$ & Date & $\begin{array}{c}\text { Initial water- } \\
\text { table depth } d_{i} \\
(\mathrm{~m})\end{array}$ & $\begin{array}{c}T_{i} \\
\left(10^{-5} \mathrm{~m}^{2} / \mathrm{s}\right)\end{array}$ & $\begin{array}{c}S_{i} \\
\left(10^{-4}\right)\end{array}$ \\
\hline 1 & $27 / 01 / 2007$ & 10.14 & 4.3 & 2.1 \\
2 & $26 / 05 / 2007$ & 15.12 & 2.3 & 1.6 \\
3 & $10 / 06 / 2007$ & 20.63 & 2.9 & 1.5 \\
4 & $12 / 06 / 2007$ & 17.17 & 2.6 & 1.6 \\
5 & $19 / 06 / 2007$ & 21.23 & 2.8 & 1.4 \\
6 & $21 / 06 / 2007$ & 19.49 & 2.3 & 1.4 \\
7 & $23 / 06 / 2007$ & 16.73 & 2.3 & 1.5 \\
8 & $29 / 06 / 2007$ & 19.63 & 3.4 & 1.7 \\
9 & $03 / 07 / 2007$ & 18.60 & 3.7 & 1.9 \\
10 & $05 / 07 / 2007$ & 13.33 & 4.1 & 1.8 \\
11 & $12 / 08 / 2007$ & 8.35 & 4.9 & 2.0 \\
12 & $25 / 08 / 2007$ & 7.57 & 5.6 & 2.0 \\
13 & $05 / 09 / 2007$ & 7.35 & 4.2 & 1.4 \\
14 & $10 / 09 / 2007$ & 6.78 & 5.4 & 1.7 \\
15 & $19 / 09 / 2007$ & 3.58 & 6.9 & 1.9 \\
16 & $22 / 09 / 2007$ & 3.45 & 6.9 & 2.1 \\
17 & $29 / 09 / 2007$ & 3.40 & 5.9 & 1.7 \\
18 & $05 / 07 / 2008$ & 13.02 & 5.4 & 2.7 \\
19 & $07 / 07 / 2008$ & 13.71 & 5.2 & 2.7 \\
20 & $19 / 07 / 2008$ & 13.72 & 5.4 & 2.6 \\
21 & $25 / 07 / 2008$ & 16.08 & 4.5 & 3.6 \\
22 & $09 / 08 / 2008$ & 11.25 & 5.4 & 3.0 \\
23 & $19 / 08 / 2008$ & 9.93 & 5.9 & 2.6 \\
24 & $21 / 08 / 2008$ & 10.15 & 5.4 & 2.8 \\
\hline & Average & $\mathbf{1 2 . 5 2}$ & $\mathbf{4 . 5}$ & $\mathbf{2 . 1}$ \\
\hline & Standard deviation & $\mathbf{5 . 5}$ & $\mathbf{1 . 4}$ & $\mathbf{0 . 0 6}$ \\
\hline & Coefficient of variation & $\mathbf{0 . 4 4}$ & $\mathbf{0 . 3 2}$ & $\mathbf{0 . 2 9}$ \\
\hline
\end{tabular}

